\title{
How reliable is the monitoring of permanent vegetation plots? A test with multiple observers
}

\author{
Pascal Vittoz ${ }^{1 *} \&$ Antoine Guisan ${ }^{2}$ \\ ${ }^{1}$ University of Lausanne, Faculty of Earth Sciences and Environment, Bâtiment Biophore, \\ CH-1015 Lausanne, Switzerland, Pascal.Vittoz@unil.ch; ${ }^{2}$ University of Lausanne, \\ Department of Ecology and Evolution, CH-1015 Lausanne, Switzerland, \\ Antoine.Guisan@unil.ch; \\ *Author for correspondence: Tel +41 2169242 70; Fax +41 216924265
}

\begin{abstract}
Questions: A multiple plots design was developed for permanent vegetation plots. How reliable are the different methods used in this design and which changes can we measure ?
\end{abstract}

Location: Alpine meadows (2430 m) in the Swiss Alps.

Methods: Four inventories were obtained from $40 \mathrm{~m}^{2}$-plots: four subplots $\left(0.4 \mathrm{~m}^{2}\right)$ with a list of species, two $10 \mathrm{~m}$-transects with the point method (50 points on each), one subplot $\left(4 \mathrm{~m}^{2}\right)$ with a list of species and visual cover estimates as a percentage and the complete plot $\left(40 \mathrm{~m}^{2}\right)$ with a list of species and visual estimates in classes. This design was tested by 5-7 experienced botanists in three plots.

Results: Whatever the sampling size, only $45-63 \%$ of the species were seen by all the observers. However, the majority of the overlooked species had a cover $<0.1 \%$. Pairs of observers overlooked $10-20 \%$ less species than single observers. The point method was the best method for cover estimate, but it took much longer than visual cover estimates, and 100 points allowed for the monitoring of only a very limited number of species. The visual estimate as a percentage was more precise than classes. Working in pairs did not improved the estimates, but one botanist that repeats the survey is more reliable than a succession of different observers.

Conclusion: Lists of species are insufficient for monitoring. It is necessary to add cover estimates to allow for subsequent interpretations in spite of the overlooked species. The choice of the method depends on the available resources: the point method is long but gives precise data for a limited number of species, while visual estimates are quick and exhaustive but allow for recording only large cover changes Constant pairs of observers improve the reliability of the records.

Keywords: Point method; Pseudoturnover; Sampling error; Species richness; Visual cover estimate. 


\section{Introduction}

Our environment is constantly changing. Changes can occur naturally, yet since the beginning of the 20th century, human influences have led to heavy modifications of ecosystems. These changes are rather big, and thus they are susceptible to influencing vegetation. Climate change has already been shown to trigger significant changes in vegetation communities (e.g., Grabherr et al. 1994; Theurillat \& Guisan 2001; Walther et al. 2002). Atmospheric pollution, nitrogen deposition (e.g. Schäppi \& Körner 1997; Stevens et al. 2004) and the strong decrease of agricultural activities in mountains (Motta \& Nola 2001; Vittoz et al. submitted) are other causes of changes in vegetation.

Many studies have used models to predict changes in species distribution, at large spatial scales (e.g., Europe; Bakkenes et al. 2002; Thuiller et al. 2005), but also at local scales (e.g., alpine environments; Guisan \& Theurillat 2000; Dirnböck et al. 2003) under various scenarios of climate change. These predictions are hypotheses that will require testing at some stage in the future. Appropriate monitoring networks are needed to test these scenarios (Guisan \& Theurillat 2005), whose designs need to be appropriate both in terms of the spatial arrangement of the plots (e.g., along elevation transects) and of sampling methods within each plot. Whereas the former is obvious (we need to be able to quantify shifts from plots to plots), the latter is rarely, or at least insufficiently, addressed. Yet, if shifts in species distribution or vegetation changes are to be detected, measurements need to be accurate.

Permanent plots have become essential tools for monitoring vegetation. Several biomonitoring projects have been set up over the last decade. The European GLORIA project (Pauli et al. 2004), aiming to monitor changes in mountain vegetation under changing climate, or the monitoring of plant diversity and the invasion of exotic species (Stohlgren et al. 2000) are examples of projects using permanent plots. In Switzerland, the programme BDM (Hintermann et al. 2002) was set up to monitor biodiversity nationwide. It was later complemented by the PeRMANENT.PlOT.CH project (Vittoz \& Guisan 2003), aiming to develop a data bank of historical and contemporary vegetation plots and to establish new permanent plots in a way adequately complementing existing ones.

Two elements are generally considered in plant inventories: the presence of species, listed as exhaustively as possible, and their abundance or cover. The cover is often estimated visually, as this is the quickest way to obtain such data. However, it is sometimes not estimated reliably enough, and some monitoring studies prefer to use only presence data (e.g., Rodwell et al. 1996; Hintermann et al. 2002). However, these methods are not objective because overlooked species are common (Lepš \& Hadincová 1992; Klimeš et al. 2001; Scott \& Hallam 2002; Kercher et al. 2003; Archaux et al. 2006), nor are they able to record changes other than the appearance or disappearance of species.

The choice of an appropriate method for cover estimation is often facing two options: monitoring small plots with accurate methods or monitoring larger plots with coarse estimates. The point method (Levy \& Madden 1933) or the $1 \mathrm{~m}^{2}$-grid with 100 cells for frequency count (Pauli et al. 2004) belong to the first category. They are quite objective, but time consuming (Everson et al. 1990), and allow for monitoring of only very small vegetation plots. On the opposite side, visual estimates of plant cover over plots of larger sizes, like the semi-quantitative Braun-Blanquet's scale (Braun-Blanquet 1964), allow for quicker surveys, but with less reliable results (Smith 1944; van Hees \& Mead 2000).

One solution to avoid such a choice is to combine different types of inventories into a multiple plots design (e.g., a large plot with several small subplots in it). This is at the basis of 
the Whittaker plots concept (Shmida 1985) and its derivative (Stohlgren et al. 1995), or the European GLORIA project (Pauli et al. 2004). But whatever the chosen method, before using it for long-term monitoring, it should be thoroughly tested and the expected reliability measured (Scott \& Hallam 2002). In particular, what needs to be tested is the minimum vegetation change that can be detected and the associated reliability. One way to estimate the reliability of a method is to test it across a range of observers.

The aims of this study were to test the reliability of different sampling techniques combined in a permanent vegetation plot. In particular, our goal was to answer the following questions: (i) how exhaustive are species lists established in plots of different surface areas $\left(0.4 \mathrm{~m}^{2}, 4 \mathrm{~m}^{2}\right.$ and $\left.40 \mathrm{~m}^{2}\right)$; (ii) how reliable are visual cover estimates, made as a percentage or in classes, compared to more quantitative estimates based on the point method; (iii) is there a difference between vegetation cover estimated by single versus pairs of observers; and, finally, (iv) is the consistency of one observer repeatedly sampling the same plot over time better than that of distinct observers over time?

Table 1. Main species observed by one observer in the three sampled plots, with visual cover estimate in classes (Table 2). Complete inventories are in the supplemental archives (Appendices 1-3).

\begin{tabular}{|c|c|c|c|}
\hline Plot & $\mathrm{dS}$ & oS & oP \\
\hline Aspect & SSE & ESE & $\mathrm{S}$ \\
\hline Slope $\left[{ }^{\circ}\right]$ & 5 & 20 & 15 \\
\hline Plants cover $[\%]$ & 89 & 49 & 70 \\
\hline Mean vegetation height $[\mathrm{m}]$ & 0.15 & 0.07 & 0.08 \\
\hline Stones cover $[\%]$ & 8 & 41 & 27 \\
\hline Carex foetida & 3 & & \\
\hline Alchemilla vulgaris aggr. & $2 \mathrm{a}$ & & \\
\hline Poa supina & $2 \mathrm{a}$ & & \\
\hline Taraxacum spec. & $1 \mathrm{a}$ & & \\
\hline Achillea millefolium & $1 \mathrm{a}$ & & \\
\hline Phleum rhaeticum & $2 b$ & $+\mathrm{b}$ & $+\mathrm{a}$ \\
\hline Poa alpina & $2 b$ & 1a & $+\mathrm{b}$ \\
\hline Potentilla aurea & $2 b$ & $1 b$ & $+\mathrm{a}$ \\
\hline Festuca rubra aggr. & $1 b$ & $+\mathrm{b}$ & \\
\hline Ligusticum mutellina & $1 \mathrm{a}$ & $1 \mathrm{a}$ & $+\mathrm{b}$ \\
\hline Geum montanum & $1 \mathrm{a}$ & $2 \mathrm{a}$ & $2 \mathrm{a}$ \\
\hline Nardus stricta & $+\mathrm{b}$ & $2 \mathrm{a}$ & $2 \mathrm{a}$ \\
\hline Festuca halleri & $+\mathrm{a}$ & $2 \mathrm{a}$ & $+\mathrm{a}$ \\
\hline Trifolium alpinum & $+\mathrm{a}$ & $+\mathrm{b}$ & $2 b$ \\
\hline Leontodon helveticus / hispidus & $1 \mathrm{a}$ & 1a & $2 \mathrm{a}$ \\
\hline Vaccinium myrtillus & & & $2 \mathrm{a}$ \\
\hline Ranunculus villarsii & $+\mathrm{a}$ & $1 b$ & \\
\hline Achillea erba-rotta subsp. moschata & $\mathrm{r}$ & $1 b$ & \\
\hline Plantago alpina & $\mathrm{r}$ & 1a & $\mathrm{r}$ \\
\hline Anthoxanthum odoratum aggr. & $+\mathrm{b}$ & 1a & $+\mathrm{b}$ \\
\hline Avenella flexuosa & & $+\mathrm{a}$ & $1 \mathrm{~b}$ \\
\hline
\end{tabular}

\section{Materiel and Methods}

\section{Study site and sampling period}

The experiment took place in the region of the Grand St-Bernard Pass in Switzerland $\left(45^{\circ} 54^{\prime} \mathrm{N}, 7^{\circ} 10^{\prime} \mathrm{E}\right)$, at an elevation of $2430 \mathrm{~m}$ a.s.l. in alpine meadows. The region is characterized by a wet alpine climate. Three plots were selected close to each other. dS was located on a flat area, on rich and deep soil with a dense sward dominated by Carex foetida, Alchemilla vulgaris aggr., Poa supina, P. alpina and Phleum rhaeticum (Table 1; 48 species). $\mathbf{o S}$ and $\mathbf{o P}$ were located on gentle, rocky slopes, with open swards, on dry and acidic soils 
dominated by Nardus stricta, Geum montanum, Festuca halleri, Leontodon helveticus, Trifolium alpinum and Vaccinium myrtillus (Table 1; 49 species in oS and 43 in oP). Complete inventories are given in the supplemental archives (App. 1-3) and nomenclature follows Aeschimann et al. (1996).

As it was not possible to have all botanists available on the same days, inventories were conducted on the 6 days between the 15th and 27th July 2004. This period was short enough to minimise phenological differences among plants during the experiment.

\section{Field sampling}

In order to make the sampling method widely usable and to keep costs as low as possible, two conditions were set for the choice of method: it should be generalizable to all types of vegetation and the inventory of the complete plot and subplots should not exceed a maximum time of about half a day. The first trials were conducted with the modifiedWhittaker plot approach (Stohlgren et al. 1995), with reduced plots $\left(40 \mathrm{~m}^{2}\right)$ to adapt to heterogeneous mountain environments. These trials were not convincing because the 10 smaller subplots proved unreliable (it was difficult to conserve the exact positions of these subplots without permanent marks in the field). We replaced them with four subplots in the corners (instead of only two corners in the original approach), and two 10m-transects based on the point method (Levy \& Madden 1933).

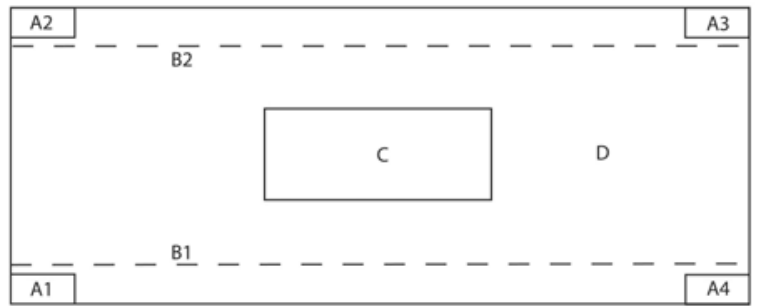

Fig. 1. Plot design with four levels of inventories: four A subplots $\left(0.4 \mathrm{~m}^{2}\right)$ with lists of species, two B transects with point method along $10 \mathrm{~m}$-lines (50 points per line), $\mathrm{C}$ subplot $\left(4 \mathrm{~m}^{2}\right)$ with list of species and cover estimate in $\%$, and D plot $\left(40 \mathrm{~m}^{2}\right)$ with list of species and cover estimate in classes (Tab. 2).

The plot size $\left(40 \mathrm{~m}^{2}\right)$ corresponds to values generally suggested to have a large proportion of the species pools in grasslands (Mueller-Dombois \& Ellenberg 1974). Each surveyed plot included the following inventories (Fig. 1):

- A subplots: four subplots, A1-A4, of $0.4 \mathrm{~m}^{2}$ each, one set on each corner of the larger plot, with dimensions $0.4 \times 1 \mathrm{~m}$; a list of species present was performed (no abundance).

- B transects: the point method (Levy \& Madden 1933) was applied along two 10m-transects, B1 and B2, with 50 sampling points distributed every $20 \mathrm{~cm}$; a thin metallic bar was placed at each point along the transects and every species touching the bar was counted (only once per point); as this method may damage the grass if repeated in a short time, a $20 \mathrm{~m}$-line close to the plots with similar vegetation was selected for each plot in this experiment;

- C subplot: a centre subplot of $4 \mathrm{~m}^{2}$, with dimensions $1.26 \times 3.16 \mathrm{~m}$ to align the corners on the plot diagonals; a complete list of species and cover estimates as a percentage were performed; the smallest allowed value for cover was set to $0.01 \%$.

- D plot: the entire plot of $40 \mathrm{~m}^{2}$, with dimensions 4 x $10 \mathrm{~m}$; a list of species and cover estimates in classes were performed (10 classes, modified from Braun-Blanquet 1964; Tab. 2). 
Table 2. Cover classes modified from Braun-Blanquet (1964) and median values used for analyses for cover estimate of the species in the D plot.

\begin{tabular}{ccc}
\hline Class & Cover [\%] & $\begin{array}{c}\text { Value for } \\
\text { analyses [\%] }\end{array}$ \\
\hline $\mathrm{r}$ & $<0.1$ & 0.05 \\
$+\mathrm{a}$ & $0.1-0.5$ & 0.3 \\
$+\mathrm{b}$ & $0.6-1$ & 0.8 \\
$1 \mathrm{a}$ & $1.1-3$ & 2 \\
$1 \mathrm{~b}$ & $3.1-5$ & 4 \\
$2 \mathrm{a}$ & $6-15$ & 10 \\
$2 \mathrm{~b}$ & $16-25$ & 20 \\
3 & $26-50$ & 37.5 \\
4 & $51-75$ & 62.5 \\
5 & $>75$ & 87.5 \\
\hline
\end{tabular}

Eight botanists participated in the experiment, but time was insufficient to allow everyone to conduct every inventory of all three plots (Tab. 3). All participants had good skills in field botany. As we did not want to test the capacity of everyone to recognize the different species, the experiment started with a reminder of all species in situ. Everyone could, at any time, verify a species' identification during the experiment, but, of course, could not pick up material in the plots or damage the vegetation. After all observers finished their censuses, the first author compared the species lists to check species occurrences that only one or two had recorded and established a full, corrected list of species present in each plot and subplot. Wrong records were not corrected before analyses, but the right total number of species was used to calculate the proportion of species seen. Time for inventories was not limited and plot frames were left in place between observers during the whole experiment. These results do not consider the problem of relocation of the plots.

Table 3. Number of inventories performed by the eight botanists during the experiment (15-27.07.2004). Plots were inventoried by a single botanist in dense (dS) and open $(\mathrm{oS})$ vegetation, and by a pair of botanists in open vegetation $(\mathrm{oP})$.

\begin{tabular}{|c|c|c|c|c|c|c|c|c|c|c|}
\hline \multirow[t]{2}{*}{ Plot } & \multirow[t]{2}{*}{ Method } & \multicolumn{8}{|c|}{ Botanist } & \multirow{2}{*}{$\begin{array}{c}\text { Number of } \\
\text { replicates }\end{array}$} \\
\hline & & $\mathrm{A}$ & $\mathrm{B}$ & $\mathrm{C}$ & $\mathrm{D}$ & E & $\mathrm{F}$ & G & $\mathrm{H}$ & \\
\hline \multirow[t]{4}{*}{$\overline{\text { dS }}$} & $\mathrm{A}$ & 1 & 1 & 1 & 1 & 1 & & 1 & 1 & 7 \\
\hline & B & 1 & 1 & 1 & & 1 & & 1 & & 5 \\
\hline & $\mathrm{C}$ & 3 & 3 & 1 & 1 & 1 & & 1 & 1 & 7 \\
\hline & $\mathrm{D}$ & 3 & 3 & 1 & & 1 & & 1 & & 5 \\
\hline \multirow[t]{4}{*}{$\overline{\text { oS }}$} & A & 1 & 1 & & 1 & 1 & 1 & 1 & 1 & 7 \\
\hline & B & 1 & 1 & & 1 & 1 & 1 & & 1 & 6 \\
\hline & $\mathrm{C}$ & 3 & 3 & & 1 & 1 & 1 & 1 & 1 & 7 \\
\hline & $\mathrm{D}$ & 3 & 3 & & 1 & 1 & 1 & & 1 & 6 \\
\hline \multirow[t]{4}{*}{$\mathbf{o P}$} & $\mathrm{A}$ & 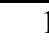 & 1 & & 1 & & & & 1 & 4 \\
\hline & B & 1 & 1 & & 1 & & & & 1 & 4 \\
\hline & $\mathrm{C}$ & 3 & 3 & & 1 & & & & 1 & 4 \\
\hline & $\mathrm{D}$ & 3 & 3 & & 1 & 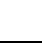 & 1 & & 1 & 4 \\
\hline
\end{tabular}

Plots dS and oS were inventoried by single observers to assess the influence of meadow density (dense vs open) on the species lists. Plot oS (single observers) was compared with oP (pairs of observers) to estimate whether working in pairs improved survey quality over single observers (Tab. 3). The risk of confounding method (single vs pair) with plot is limited by the similarity of structure and composition between plots (Tab. 1) and the use of pseudoturnover and mean coefficient of variation analyses, which do not directly depend on 
species composition. It would not have been possible to twice inventory the same plot by the same botanists, once alone and once by pairs. In order to test if a botanist who re-surveyed the same plot at different time intervals was more trustworthy than distinct botanists, the first author and a colleague, who had a two years of experience in working together, each sampled plots dS and oS three times (replicate inventories). The first inventory was standard, while those following were limited to cover estimates of $\mathrm{C}$ and $\mathrm{D}$ plots, based on the first lists. Each inventory was separated by 3-7 days: this is considered long enough to forget previous cover estimates, especially as we meanwhile worked in other regions, but not long enough to forget the presence of rare or cryptic species. Data from the two botanists were pooled to get a sufficient number of replicates.

\section{Data Analyses}

Morphologically close species, difficult to recognize in a sterile state, were pooled in the analyses (e.g., Leontodon helveticus and L. hispidus or Lotus corniculatus and L. alpinus).

Differences in species composition between two species lists separated in time can be due either to real changes (species turnover) and/or to errors (overlooked species). The data may be compared by the observed turnover rate (percentage of unpaired records) and the proportion of common species. In this experiment, involving almost simultaneous inventories, only observer errors can explain the differences. The unpaired records thus represent the pseudoturnover rate between botanists and the proportion of common species is the proportion of species that every botanist successfully detects. The pseudoturnover (PT) was calculated according to Nilsson \& Nilsson (1985) as

$$
\mathrm{PT}=100 *(\mathrm{X}+\mathrm{Y}) /\left(\mathrm{S}_{\mathrm{X}}+\mathrm{S}_{\mathrm{Y}}\right)
$$

where $\mathrm{X}$ and $\mathrm{Y}$ are the numbers of species recorded exclusively by each observer, and $\mathrm{S}_{\mathrm{X}}$ and $\mathrm{S}_{\mathrm{Y}}$ are the total numbers of species recorded by each of them. For each sampling method, the PTs of one observer with the others were averaged. These averages for the different methods were compared with t-tests.

The proportion of species seen by every botanist during one inventory was calculated by referring to the exhaustive species list. The data from the four A subplots (A1-A4) were averaged. For the $\mathrm{C}$ subplots and the $\mathrm{D}$ plots, the average cover estimates (see below) of the overlooked species were used to calculate the limit of visibility. Two measures were used in the comparisons: the overlooked species with the highest mean cover and the median of mean covers of all overlooked species.

For the comparison between cover estimates, the values for the $\mathrm{C}$ subplots were used without modification, while the number of contacts along the B transects were used as percent cover and the median value of every cover class was used for the D plot (Table 1). The latter transformation allows comparison of results from D plots with those of the B transects and $\mathrm{C}$ subplots. Therefore, one has to keep in mind the complete range of classes when considering the results of the D plot analyses.

The coefficient of variation $(\mathrm{CV})$ was calculated for the cover estimates of plants as

$$
\mathrm{CV}=100 * \mathrm{SD} / \mathrm{M}
$$

where $\mathrm{SD}$ is the standard deviation and $\mathrm{M}$ is the mean of the cover estimated by every botanist (Helm \& Mead 2004). Only species seen by all botanists or overlooked by only one were considered. The different methods were compared with a t-test applied to the mean cover values across these species.

As the cover estimates are subjective, it is necessary to calculate the cover changes that can be considered as significant, or, in other words, which difference is larger than the 
variability between observers. The estimated covers were grouped by pairs: each cover estimate is put next to another estimate for the same species in the same plot. This is repeated for all cover estimates across all botanists and plants. Thus, six botanists per plot yield 30 possible pairs of estimates per species. Next, the pairs were sorted according to the first estimate (all $0.01 \%$ together, all $0.02 \%$, etc.) and the quantiles of 10 and $90 \%$ were calculated for values associated with 10 or more other estimates. We retained these quantile values because they kept a reasonable precision with the available data (quantiles of 5 and $95 \%$ would have required to retain only values associated with 20 or more other estimates). We used the Super Smoother function supsmu(x, y) in S-PLUS 2000 Professional (Insightful Corp.) to draw trend lines across the scatter plots of these $10 \%$ and $90 \%$ quantiles.

Table 4. Comparison of pseudoturnovers (mean in $\% \pm \mathrm{SD}$, number of replicates in brackets) for plant inventories in the A subplots, the $\mathrm{C}$ subplot and the $\mathrm{D}$ plot.

\begin{tabular}{lccc}
\hline Method & $\mathrm{dS}$ & $\mathrm{oS}$ & $\mathrm{oP}$ \\
\hline $\mathrm{A}\left(0.4 \mathrm{~m}^{2}\right)$ & $18.9 \pm 8.0(7)$ & $14.6 \pm 5.8(7)$ & $13.7 \pm 8.9(4)$ \\
$\mathrm{C}\left(4 \mathrm{~m}^{2}\right)$ & $16.7 \pm 6.9(7)$ & $9.2 \pm 3.2(7)$ & $5.2 \pm 2.1(4)$ \\
$\mathrm{D}\left(40 \mathrm{~m}^{2}\right)$ & $12.3 \pm 2.9(5)$ & $13.3 \pm 3.7(6)$ & $9.3 \pm 2.8(4)$ \\
\hline
\end{tabular}

\section{Results}

\section{Species lists}

The mean pseudoturnover often exceeds 10\% (Tab. 4). For the $\mathrm{C}$ and A subplots, the values are significantly higher in dense $(\mathrm{dS}, \mathrm{p}<0.001)$ than in open vegetation $(\mathrm{oS}, \mathrm{p}=$ 0.003 ), but this does not hold for the larger D plot. Species are easier to detect in open vegetation. This is confirmed by the proportion of species seen by all botanists (Tab. 5). In such dense meadows, this proportion may drop to less than $50 \%$. The pseudoturnover gets smaller when two observers work together (oS vs. oP, $\mathrm{p}<0.01$ for $\mathrm{C}$ subplots and D plots) (Tab. 4). There are no differences for A subplots, but the value should have been lower in oP: one of the corners had a very irregular surface (some species were hidden below a big rock), which induced inaccuracies in the definition of the limits (the mean on the three other corners for oP is $10.0 \pm 5.3, \mathrm{p}=0.001$ compared to $\mathrm{oS}$ ). The improvement brought by two observers is also evident when looking at the proportion of species observed by all the botanists, with an increase of 10-20\% (Tab. 5).

Table 5. Proportion (in \%) of the species seen by all the botanists and visibility limit (estimated cover in \%) of the overlooked species expressed as the overlooked species with the highest mean cover (Visibility limit) and as the median of mean covers of all overlooked species. Sampled plots were $0.4 \mathrm{~m}^{2}$ (A), $4 \mathrm{~m}^{2}$ (C) and $40 \mathrm{~m}^{2}$ (D) and were inventoried by a single botanist in dense (dS) and open (oS) vegetation, and by a pair of botanists in open vegetation (oP).

\begin{tabular}{|c|c|c|c|c|c|c|c|}
\hline & \multicolumn{3}{|c|}{ Proportion of species seen $[\%]$} & \multicolumn{2}{|c|}{ Visibility limit [\%] } & \multicolumn{2}{|c|}{$\begin{array}{c}\text { Median of overlooked } \\
\text { species [\%] }\end{array}$} \\
\hline & $\bar{A}$ & $\mathrm{C}$ & $\mathrm{D}$ & $\mathrm{C}$ & $\bar{D}$ & $\mathrm{C}$ & $\mathrm{D}$ \\
\hline $\mathrm{dS}$ & 39.0 & 45.5 & 58.3 & 1.43 & 1.15 & 0.05 & 0.05 \\
\hline oS & 49.1 & 63.3 & 59.2 & 0.53 & 0.54 & 0.01 & 0.13 \\
\hline $\mathrm{oP}$ & 62.8 & 83.3 & 69.8 & 0.26 & 0.18 & 0.03 & 0.05 \\
\hline
\end{tabular}


The same trend is shown with the species' limit of visibility. A single observer overlooked species with cover exceeding $1 \%$ in dense grassland, whereas this limit fell to around $0.5 \%$ in open grassland and to below $0.3 \%$ when working in pairs (Tab. 5 , visibility limit). Overlooking species that have a high cover is exceptional and, in most cases, overlooked species had a cover below $0.1 \%$ (Tab. 5 , median of overlooked species).

The analyses were conducted a second time in $\mathrm{dS}$ and oS with only the four most experienced botanists, which corresponds to a selection test before the survey to engage the most skilled botanists (results not shown). This obviously resulted in slightly better results, but even very experienced botanists overlooked some species. This is likely to occur in any survey.

The area of the plots had an unclear influence on the results. The small A subplots $(0.4$ $\mathrm{m}^{2}$ ) always had the highest pseudoturnover (Tab. 4) and the lowest proportion of species recorded by all observers (Tab. 5), but not all differences were significant. In open vegetation, the $C$ subplots $\left(4 \mathrm{~m}^{2}\right)$ had a significantly lower pseudoturnover than the D plots $\left(40 \mathrm{~m}^{2}\right)$ (Tab. $4, \mathrm{p}<0.01$ for oS and oP), but the opposite was observed in dense vegetation, although not significant (Tab. $4, \mathrm{p}=0.107$ ).

\section{Cover estimates}

The point method ( $\mathrm{B}$ transects) proved to have by far the lowest coefficient of variation (Fig. 2) and to be almost always significantly different from the visual estimates as a percentage $(\mathrm{C}$ subplot) or in classes $(\mathrm{D}$ plot $)(\mathrm{p}<0.01$, except for $\mathrm{D}$ in oP). However, the point method provided data for a smaller number of species than the other methods (Fig. 2). Many species were too scattered to be detected by this method.

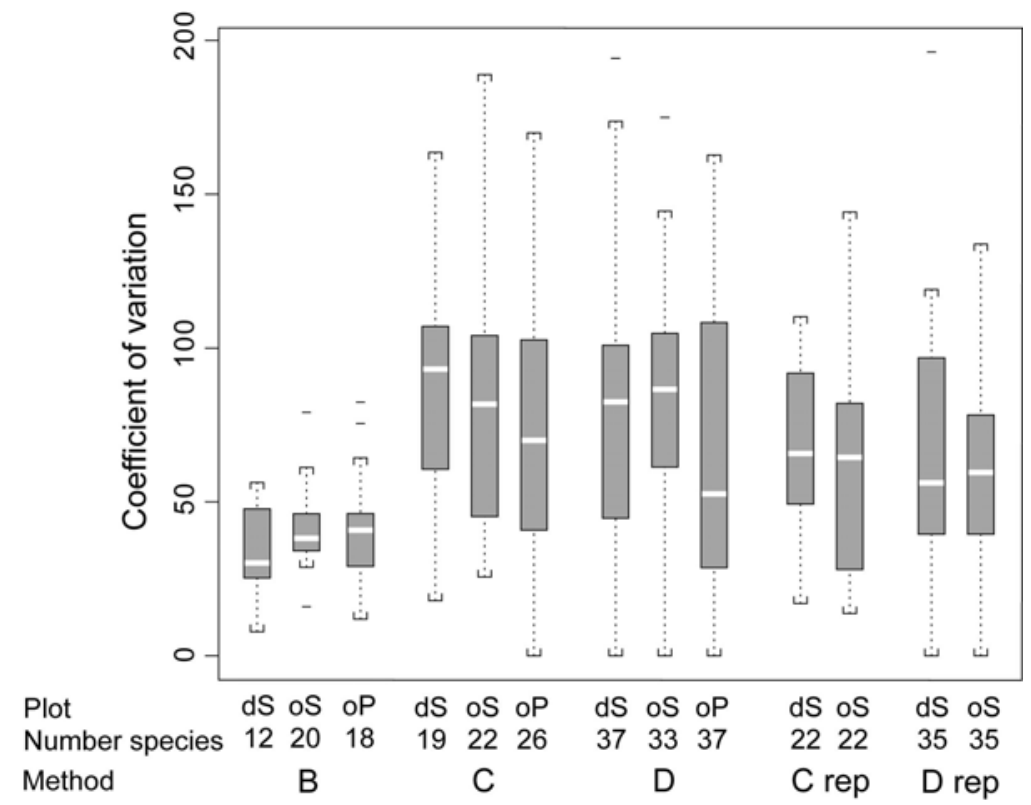

Fig. 2. Boxplots of the coefficients of variation for cover estimates with the point method (B transects), visual as a percentage (C subplot) or in classes (D plot). Inventories were performed by single botanists in dense (dS) and open $(\mathrm{oS})$ vegetation, and by a pairs of botanists in open vegetation (oP). C rep and D rep are the replicates of two experienced botanists for the same surfaces. The species considered in the average were species seen by all botanists or all except one. The median, the upper and lower quartiles (ends of box), the whiskers (nearest value not beyond $1.5 *$ inter-quartile range) and the outliers are represented. 
The two visual cover estimate methods had similar coefficients of variation (Fig. 2), as these never differed significantly. However, when considering the limits of detectable change between two successive surveys, the cover estimate as a percentage is clearly superior, as these are narrower than in classes (Fig. 3). This difference increases even more strongly when the cover limits are translated into classes (App. 4).
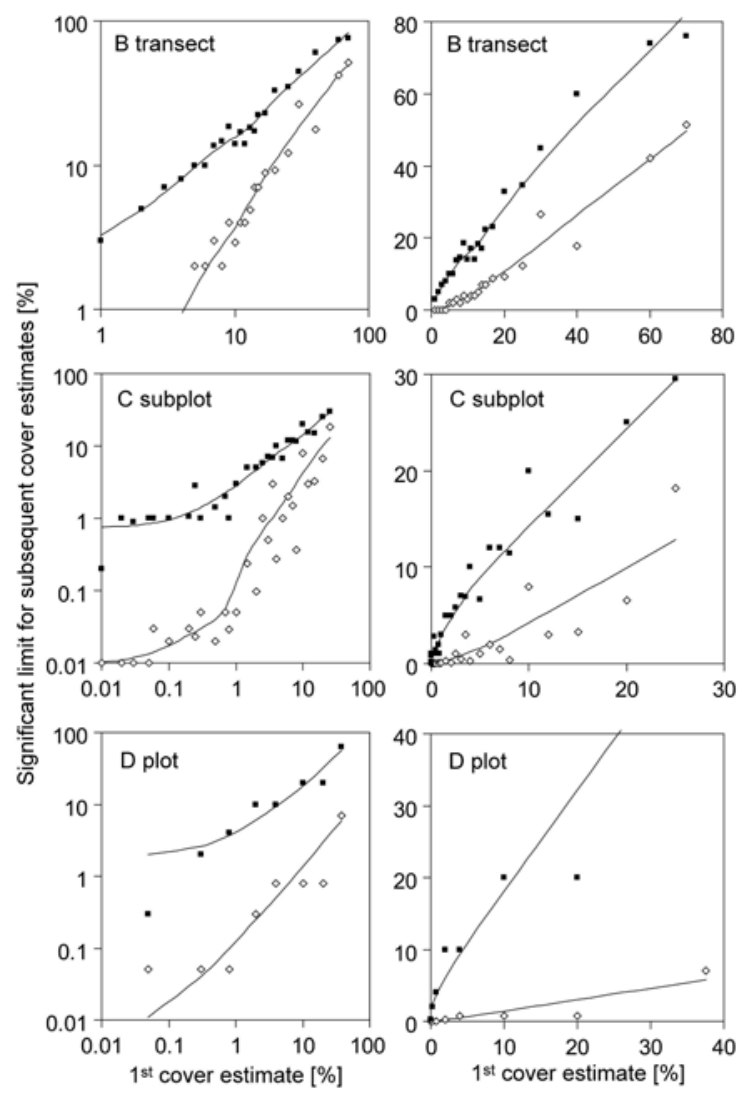

Fig. 3. Limits for cover estimates which can be considered different from a first estimate (lower curves for quantile $10 \%$ and upper curves for quantile $90 \%$ ): point method (B transects), visual estimate as a percentage (C subplot) and in classes (D plot). Values calculated for single observers in plots with dense (dS) and open (oS) vegetation (left graphic with logarithmic scales). A table for some precise values is given in the supplemental archives (App. 4).

The limits of visual cover estimates as a percentage are very large for species with a high cover (Fig. 3 right). In relative values, however, the limits decrease strongly as cover increases (Fig. 3 left). Unfortunately, the large majority of species have low covers and this will restrict the possibility to record their changes.

Working in pairs did not improve the cover estimates, as shown by comparing the coefficients of variation of $\mathrm{oS}$ and oP (Fig. 2, Tab. $6 ; \mathrm{p}=0.380$ for $\mathrm{C}$ subplots and $\mathrm{p}=0.059$ for D plots). However, a repeated survey by a same observer is likely to improve the reliability of cover estimate (Fig. 2). However, the difference was small and not always significant, although it was clear by examining the significant limits for different cover estimates (Tab. 6). 
Table 6. Limits for cover estimates which can be considered different from a first estimate (under the quantile $10 \%$ or above the quantile $90 \%$ ) dependent on the observers: single botanists, botanists which replicate the cover estimate on the same plot and pairs of botanists working together. Values are calculated for visual estimates as a percentage (C subplot) in dense (dS) and open (oS) vegetation for Single and Replicate, and in open vegetation for Pairs (oP).

\begin{tabular}{ccccccccc}
\hline & \multicolumn{2}{c}{ Single } & & \multicolumn{2}{c}{ Replicate } & & \multicolumn{2}{c}{ Pairs } \\
\cline { 2 - 3 } \cline { 8 - 9 } $1^{\text {st }}$ estimation & $10 \%$ & $90 \%$ & & $10 \%$ & $90 \%$ & & $10 \%$ & $90 \%$ \\
\hline 0.01 & 0.01 & 0.74 & & 0.02 & 0.53 & & 0.01 & 0.62 \\
0.02 & 0.01 & 0.77 & & 0.02 & 0.55 & & 0.01 & 0.64 \\
0.05 & 0.01 & 0.83 & & 0.02 & 0.60 & & 0.01 & 0.69 \\
0.1 & 0.02 & 0.94 & & 0.03 & 0.69 & & 0.02 & 0.78 \\
0.2 & 0.02 & 1.2 & & 0.04 & 0.88 & & 0.05 & 0.93 \\
0.5 & 0.04 & 1.8 & & 0.07 & 1.4 & & 0.16 & 1.4 \\
1 & 0.13 & 2.8 & & 0.26 & 2.2 & & 0.37 & 2.2 \\
2 & 0.49 & 4.6 & & 0.83 & 3.5 & & 0.81 & 3.9 \\
5 & 1.6 & 8.9 & & 2.8 & 7.5 & & 2.2 & 9.2 \\
10 & 4.2 & 14.2 & & 6.0 & 13.6 & & 3.8 & 16.0 \\
15 & 7.1 & 19.3 & & 9.2 & 19.8 & & 5.4 & 22.7 \\
20 & 10.0 & 24.4 & & & & & \\
\hline
\end{tabular}

\section{Discussion}

The type of permanent plots design that was tested in this study is meant to allow reliable results to be obtained for sufficiently large plots $\left(40 \mathrm{~m}^{2}\right)$ in a reasonable time (about half a day per plot). Results from the multiple observers test showed that a high reliability is very difficult to achieve, especially for cover estimate, but they make it possible to determine the range of data within which any change should be interpreted with caution.

\section{Species lists}

Some authors suggested to limit plant inventories to presence-absence lists because of the subjective estimate of plant cover (Rodwell et al. 1996; Hintermann et al. 2002). However, our results show that such lists are far from reliable as well. Any botanist, even an experienced one, overlooks some species (Tab. 4). This is supported by measured pseudoturnovers of between 10 and $15 \%$, possibly even higher in dense vegetation, and a low proportion of species recorded by all observers (Tab. 5). These pseudoturnover values are close to the $13 \%$ found by Lepš \& Hadincová (1992) between two experienced botanists. Higher values have been published as well, like Scott \& Hallam (2002) with a mean pseudoturnover $>20 \%$, including bryophytes and lichens which exhibited higher pseudoturnovers than flowering plants and ferns, or Kercher et al. (2003) with a pseudoturnover of $19.1 \%$ partly due to plot placement between observers.

The relationship between the plot size and the reliability of species lists remains unclear. The smallest areas (A subplots) yielded the worst results (Tab. 4 and 5). This is contrary to what one would expect by thinking that it is easier to be exhaustive in small areas, but is in accordance with Klimeš et al. (2001), who found a higher proportion of species recorded in $4 \mathrm{~m}^{2}$-plots than in smaller ones. In our experiment, the search for species in the A subplots was probably less intensive than in larger plots because no cover estimate was required for these. Supplementary species are regularly found during this stage of the inventory (personal observation by $\mathrm{P}$. Vittoz). The trend of increasing reliability with increasing area is no more visible with larger plot size (C subplot and D plot). One can hypothesize that rare or cryptic species, overlooked in a small plot, have chances to be seen in a large plot because more individuals are present. The density of the grass may influence the 
results as well. It is more difficult to find species in dense vegetation (dS) than in open vegetation (oS; Tab. 4). The influence of vegetation type and plot size on reliability should be further examined with supplementary plots in different vegetation types, for example in forests or lowland grasslands.

As our results showed, species lists may be significantly improved by inventorying in pairs (Tab. 4 and 5; Traxler 1998). Klimeš et al. (2001) similarly showed that a second observer resulted in a $12 \%$ increase in the species recorded over the list generated by the first observer alone. Most observers have a better knowledge of some species and are more able to find them when they are rare and mixed with many other species. Moreover, the time-person investment for the inventory is almost double compared to one observer, as the necessary surveying time is generally a little shorter for pairs than for single botanists (data not shown).

Some species that were overlooked by an observer may still obtain a high cover estimation by another observer. This may be due to: (i) a misidentification of a sterile species, (ii) a species seen but forgotten in the list (disturbed concentration; Lepš \& Hadincová 1992), (iii) an artefact due to the cover being over-estimated by one of the botanists. However, most of the overlooked species had a very low cover, under 0.1\% (Tab. 5; Lepš \& Hadincová 1992; Kercher et al. 2003). This threshold may be used to interpret successive lists of species when cover estimates are available: a small cover, around $0.1 \%$ or lower, may suggest a previously overlooked species.

\section{Cover estimates}

The point method, which is generally considered an objective method to estimate plant cover (Everson \& Clarke 1987), gave the most faithful results in this experiment (Fig. 2). The coefficient of variation was about half of those from visual estimates. However, as with any random method, common species are more frequently recorded, and thus obtain precise cover estimates, whereas less frequent and rare species are largely neglected or omitted. As in natural grasslands, the large majority of plants have low cover (Lepš \& Hadincova 1992), and sampling only 100 points along a $20 \mathrm{~m}$ transect seems largely insufficient for ensuring a good monitoring. Everson et al. (1990) showed that, with 100 points, the method is able to detect changes of $25 \%$ for plants with a frequency higher than $30 \%$. In our case, this represents two species in $\mathrm{dS}$, zero in oS and three in oP. With 200 points, a number often used with the point method, one can expect a relative precision of about $20 \%$ for species with a frequency over 26\% (Everson et al. 1990), and 1200 points would be required to achieve a similar precision with species around 5\% (in our case: 7 species in dS, 13 in oS and 11 in oP). Such intensity translates into long survey times, which is usually unaffordable in standard monitoring programs as 60-120 minutes are necessary to sample 100 points in grassland (pers. obs. P. Vittoz). Moreover, this method is severely restricted by weather conditions: when wet, bent grasses bias the results, and windy conditions prevent its proper application. Only very shortgrassed meadows (e.g., high alpine meadows) or very open vegetation (e.g., undergrowth in forests or rocky environments) would be adequate for a generalization of the point method.

The visual estimates as a percentage and in classes share similar coefficients of variation (Fig. 2). The high values (mostly between 50 and 100\%) are comparable to other similar experiments (Klimeš 2003; Helm \& Mead 2004). However, plot size may influence the results. Klimeš (2003) showed that the precision increased with plot size, as tested between 0.001 and $4 \mathrm{~m}^{2}$. For larger areas, Traxler (1998) considered that the precision for visual estimate as a percentage decreases strongly above this value: it is hardly possible to have a global view of the entire plot, so estimates of the area covered by a plant by referring to some conceptual reference units (e.g., mentally visualizing if the species would fill unit 
sizes of $0.1 \%, 1 \%, 5 \%$, etc.) also becomes more difficult. For this reason, the design of our experiment retained percentages for small plots $\left(\leq 4 \mathrm{~m}^{2}\right)$ and classes for larger ones.

The improvement of plant cover estimation by working in pairs is not clear. Klimeš (2003) suggested that working in groups of three could further minimize the errors, but he did not test his assertion. In the same way, Sikes et al. (1983) calculated that it is possible to reduce the confidence interval by half by using groups of four botanists when each makes an estimate. Observers tend to overestimate or underestimate plant covers more or less consistently through experiments (Sykes et al. 1983). A pair of observers would allow averaging these unequal skills over species toward more realistic values. However, our data could not show significant improvements with pairs compared to single observers (Fig. 2, Tab. 6). This question deserves supplementary experiments.

Another way to improve the results is to make repeated inventories of the same plot by the same botanist (Fig. 2, Tab. 6). However, few experiments tested this, and those existing provided contrasted results. Sykes et al. (1983) found that a $90 \%$ confidence interval for an observer repeating an estimate on the same quadrat spanned a range of approximately \pm 5 $15 \%$ cover of the mean value, against $\pm 10-20 \%$ for an observer drawn at random. But, van Hees \& Mead (2000) concluded conversely that observers were not consistent from one measurement to the next. One large difference between these experiments is the time separating the two inventories. Sykes et al. (1983), like us, separated the inventories by only a few days (between 2 and 8) whereas van Hees \& Mead (2000) repeated them only after about 6 weeks. This means that either the consistency of observers is limited to a few days, and repeating a survey after a few weeks will be less reliable, or that the vegetation changed between the successive inventories of van Hees \& Mead (2000) (Sykes et al. 1983; Kennedy \& Addison 1987). However, the monitoring of global change's influence on vegetation will extend over one or more decades and, at this time scale, the repeatability of one botanist will certainly not be better than that from different observers.

\section{Choosing an efficient method}

Our tests highlighted the intrinsic variability that characterizes any vegetation survey. No perfect method exists for the monitoring of permanent vegetation plots. All of them are sensitive to the subjectivity of observers, and the choice of a "good" method depends primarily on the aims of the project and the available resources (time and money). As our final aim is to monitor the influence of environmental changes on Swiss vegetation, the final method to be chosen must be applicable to all types of vegetation.

A presence-absence method, as used for the A subplots, cannot be recommended. Many species are frequently overlooked, and the interpretation of the results could easily lead to erroneous conclusions. Providing a cover estimate, even roughly, is thus necessary if one must be able to distinguish real turnover (new and disappearing species) from the observer's failure to detect some species. In addition, considering supplementary information, such as reporting the developmental stage of plants (i.e., seedling, sterile or flowering; Scott \& Hallam 2002), could also help identify those detection errors.

However, our results suggest that no method is perfectly objective for estimating covers. The best one is the point method, but with a large numbers of points $(>1000)$, this is very time consuming in grassland and the result is still biased toward very abundant species (Everson et al. 1990). As most of the species are infrequent, a visual cover estimate still remains the quickest method for obtaining data on nearly all species. The question at this stage is comparable to the SLOSS paradigm (Järuinen 1982) in conservation biology for setting-up reserves. Is it better to sample a single large plot or several small plots? For small plot sizes $\left(\leq 4 \mathrm{~m}^{2}\right)$, an estimate as a percentage seems to be the best choice. However, it bears 
a high risk of omitting a part of the species pool or of missing locally restricted changes. For larger plot sizes $\left(>4 \mathrm{~m}^{2}\right)$, a class estimate seems more appropriate. This will only allow for revealing the most important, coarse changes affecting vegetation, but will bring the necessary complement to the species list.

In conclusion, efficient monitoring may not lay only on presence-absence lists of species, whatever the sampling size. Cover estimates are necessary for subsequent interpretations. The choice of the method depends on the available time (or money), as the most precise method (point method) is by far the longest. But whatever the chosen method, a multiple observer test is necessary to measure the changes which can be considered as significant during interpretation in relationship to the type of vegetation. Lists of species may be improved by working in teams and cover estimates can be improved by encouraging the constancy of observers, even if the latter might be difficult to ensure in long-term monitoring projects. Pairs of botanists are obviously more expensive, but they also improve, quicken and facilitate several other measurements in the field (marking and locating the permanent plots, measuring abiotic conditions) and they ensure a better security of observers when working in a mountainous environment.

\section{Acknowledgements}

This research has been supported by the Federal Office for the Environment FOEN (Switzerland) and the University of Lausanne. We are grateful to A. Dufour, S. Godat, S. Jutzeler, S. Maire, C. Randin and L. de Stefani for their participation in the field work experiment, to J. Goudet for his advice in statistical analysis and to P. Dixon and one anonymous reviewer for their constructive feedback on a first draft.

\section{Bibliography}

Aeschimann, D., Heitz, C., Palese, R., Perret, P. \& Moser, M. 1996. Index synonymique de la Flore de Suisse. Documenta Floristicae Helvetiae 1. Centre du Réseau Suisse de Floristique, Geneva.

Archaux, F., Gosselin, F., Bergès, L. \& Chevalier, R. 2006. Effects of sampling time, species richness and observer on the exhaustiveness of plant censuses. J. Veg. Sci. 17: 299-306.

Bakkenes, M., Alkemade, J.R.M., Ihle, F., Leemans, R. \& Latour, J.B. 2002. Assessing effects of forecasted climate change on the diversity and distribution of European higher plants for 2050. Global Change Biol. 8: 390-407.

Braun-Blanquet, J. 1964. Pflanzensoziologie. Grundzüge der Vegetationskunde. Springer, Wien.

Dirnbock, T., Dullinger, S. \& Grabherr, G. 2003. A regional impact assessment of climate and land-use change on alpine vegetation. J. Biogeogr. 30: 401-417.

Everson, T.M. \& Clarke, G.P.Y. 1987. A comparison of six methods of botanical analysis in the montane grasslands of Natal. Vegetatio 73: 47-51.

Everson, T.M., Clarke, G.P.Y. \& Everson, C.S. 1990. Precision in monitoring plant species composition in montane grasslands. Vegetatio 88: 135-141. 
Grabherr, G., Gottfried, M. \& Pauli, H. 1994. Climate effects on mountain plants. Nature 369: 448.

Guisan, A. \& Theurillat, J.-P. 2000. Assessing alpine plant vulnerability to climate change: a modeling perspective. Integr. Assess.1: 307-320.

Guisan, A. \& Theurillat, J.-P. 2005. Appropriate monitoring networks are required for testing model-based scenarios of climate change impact on mountain plant distribution. In: Huber, U.M., Bugmann, H. \& Reasoner, M.A. (eds). Global change in mountain regions Kluwer Academic Press, Dordrecht.

Hintermann, U., Weber, D., Zangger, A. \& Schmill, J. 2002. Biodiversity Monitoring in Switzerland, BDM - Interim Report. Environmental Series 342. Swiss Agency for the Environment, Forests and Landscape SAEFL, Bern.

Helm, D.J. \& Mead, B.R. 2004. Reproductibility of vegetation cover estimates in southcentral Alaska forests. J. Veg. Sci. 15: 33-40.

Järuinen, O. 1982. Conservation of endangered plant populations: single large or several small reserves ? Oikos 38: 301-307.

Kennedy, K.A. \& Addison, P.A. 1987. Some considerations for the use of visual estimates of plant cover in biomonitoring. J. Ecol. 75: 151-157.

Kercher, S.M., Frieswyk, C.B. \& Zedler, J.B. 2003. Effects of sampling teams and estimation methods on the assessment of plant cover. J. Veg. Sci. 14: 899-206.

Klimeš, L. 2003. Scale-dependent variation in visual estimates of grassland plant cover. $J$. Veg. Sci. 14: 815-821.

Klimeš, L., Dančák, M., Hájek, M., Jongepierová, I. \& Kučera, T. 2001. Scale-dependent biases of species counts in a grassland. J. Veg. Sci. 12: 699-704.

Lepš, J. \& Hadincová, V. 1992. How reliable are our vegetation analyses ? J. Veg. Sci. 3: 119124.

Levy, E.B. \& Madden, E.A. 1933. The point method of pasture analysis. N.Z.J. Agric. 46: 267-269.

Motta, R. \& Nola, P. 2001. Growth trends and dynamics in sub-alpine forest stands in the Varaita Valley (Piedmont, Italy) and their relationships with human activities and global change. J. Veg. Sci. 12: 219-230.

Mueller-Dombois, D. \& Ellenberg, H. 1974. Aims and methods of vegetation ecology. Wiley $\&$ Sons, New York.

Nilsson, I.N. \& Nilsson, S.G. 1985. Experimental estimates of census efficiency and pseudoturnover on islands: error trend and between-observer variation when recording vascular plants. J. Ecol. 73: 65-70.

Pauli, H., Gottfried, M., Hohenwallner, D., Reiter, K., Casale, R. \& Grabherr, G. 2004. The GLORIA field manual. Multi-summit approach. European Commission. Office for Official Publications of the European Communities, Luxembourg.

Rodwell, J.S., Sykes, J.M. \& Helps, M.B. 1996. Vegetation protocol. In: Sykes, J.M. \& Lane, A.M.J. (eds). The United Kingdom Environmental Change Network: Protocols for standard measurements at terrestrial sites. The Stationery Office, London.

Schäppi, B. \& Körner, C. 1997. In situ effects of elevated $\mathrm{CO}_{2}$ on the carbon and nitrogen status of alpine plants. Funct. Ecol. 11: 290-299. 
Scott, W.A. \& Hallam, C.J. 2002. Assessing species misidentification rates through quality assurance of vegetation monitoring. Plant Ecol. 165: 101-115.

Shmida, A. 1984. Whittaker's plant diversity sampling method. Israel J. Bot. 33: 41-46.

Smith, A.D. 1944. A study of the reliability of range vegetation estimates. Ecology 25: 441448.

Stevens, C.J., Dise, N.B., Mountford, J.O. \& Gowing, D.J. 2004. Impact of Nitrogen Deposition on the Species Richness of Grasslands. Science 303: $1876-1879$.

Stohlgren, T.J., Falkner, M.B. \& Schell, D. 1995. A modified-Whittaker nested vegetation sampling method. Vegetatio 117: 113-121.

Stohlgren, T.J., Owen, A.J. \& Lee, M. 2000. Monitoring shifts in plant diversity in response to climate change: a method for landscapes. Biodivers. Conserv. 9: 65-86.

Sykes, J.M., Horrill, A.D. \& Mountford, M.D. 1983. Use of visual cover assessments as quantitative estimators of some Britisch woodland taxa. J. Ecol. 71: 437-450.

Theurillat, J.-P. \& Guisan, A. 2001. Potential impact of climate change on vegetation in the European Alps: a review. Clim. Change 50: 77-109.

Thuiller, W., Lavorel, S., Araújo, M.B., Sykes, M.T. \& Prentice, I.C. 2005. Climate change threats to plant diversity in Europe. P. Natl. Acad. Sci. USA 102: 8245-8250.

Traxler, A. 1998. Handbuch des Vegetationsökologischen monitorings. Methoden, Praxis, angewandte Projekte. Teil A: Methoden. Monographien 89A. Umweltbundesamt, Wien.

van Hees, W.W.S. \& Mead, B.R. 2000. Ocular estimates of understory vegetation structure in a closed Picea glauca/Betula papyrifera forest. J. Veg. Sci. 11: 195-200.

Vittoz, P. \& Guisan, A. 2003. Le projet PeRmanent.Plot.CH demande votre collaboration. Das Projekt Permanent.Plot.ch bittet um Ihre Mithilfe. Bot. Helv. 113: 105-110.

Vittoz, P., Rulence, B. Largey, T. \& Freléchoux, F. Submitted. Effects of climate and landuse change on establishment and growth of cembran pine (Pinus cembra L.) over the altitudinal treeline ecotone in the Central Swiss Alps. Arctic Antarct. Alpine Res.

Walther, G.-R., Post, E., Convey, P., Menzel, A., Parmesan, C., Beebee, T.J.C., Fromentin, J.M., Hoegh-Guldberg, O. \& Bairlein, F. 2002. Ecological responses to recent climate change. Nature 416: 389-395.

For appendices 1-4, see JVS/AVS Electronic Archives:

www.opuluspress.se/pub/archives/index.htm 


\section{Supplemental archives}

App. 1. Records of all botanists in the dense vegetation plot (dS) for the different methods.

EXCEL file www.opuluspress.se/pub/archives/index.htm

App. 2. Records of all botanists in the open vegetation plot (oS) for the different methods.

EXCEL file www.opuluspress.se/pub/archives/index.htm

App. 3. Records of the four pairs of botanists in the open vegetation plot (oP) for the different methods.

EXCEL file www.opuluspress.se/pub/archives/index.htm

App. 4. Limits for cover estimates which can be considered different from a first estimate (under the quantile $10 \%$ or above the quantile $90 \%$ ) for three methods: point method (B transect), visual estimate as a percentage (C subplot) and in classes (D plot, corresponding classes in brackets). Values calculated for single observers in dense (plot dS) and open (oS) vegetation.

\begin{tabular}{|c|c|c|c|c|c|c|c|c|}
\hline \multicolumn{3}{|c|}{$\mathrm{B}$} & \multicolumn{3}{|c|}{$\mathrm{C}$} & \multicolumn{3}{|c|}{$\mathrm{D}$} \\
\hline $1^{\text {st }}$ estimate & $10 \%$ & $90 \%$ & $1^{\text {st }}$ estimate & $10 \%$ & $90 \%$ & $1^{\text {st }}$ estimate & $10 \%$ & $90 \%$ \\
\hline 1 & 0 & 4 & 0.01 & 0.01 & 0.74 & $0.05(\mathrm{r})$ & $0.01(\mathrm{r})$ & $2.0(1 \mathrm{a})$ \\
\hline 2 & 0 & 5 & 0.02 & 0.01 & 0.77 & $0.3(+a)$ & $0.04(\mathrm{r})$ & $2.6(1 b)$ \\
\hline 5 & 1 & 10 & 0.05 & 0.01 & 0.83 & $0.8(+b)$ & $0.10(\mathrm{r})$ & $3.6(1 b)$ \\
\hline 7 & 2 & 13 & 0.1 & 0.02 & 0.94 & $2(1 a)$ & $0.25(\mathrm{r})$ & $6.0(2 a)$ \\
\hline 10 & 3 & 16 & 0.2 & 0.02 & 1.2 & $4(1 b)$ & $0.49(+a)$ & $9.3(2 b)$ \\
\hline 15 & 7 & 22 & 0.5 & 0.04 & 1.8 & $10(2 a)$ & $1.4(+b)$ & $18.1(3)$ \\
\hline 20 & 10 & 29 & 1 & 0.13 & 2.8 & $20(2 b)$ & $3.0(1 \mathrm{a})$ & $32.2(4)$ \\
\hline 25 & 14 & 35 & 2 & 0.49 & 4.6 & $37.5(3)$ & $5.8(1 b)$ & $56.8(5)$ \\
\hline 30 & 18 & 41 & 5 & 1.6 & 8.9 & & & \\
\hline 40 & 26 & 52 & 10 & 4.2 & 14.2 & & & \\
\hline 50 & 34 & 62 & 15 & 7.1 & 19.3 & & & \\
\hline 60 & 41 & 73 & 20 & 10.0 & 24.4 & & & \\
\hline 70 & 49 & 83 & 25 & 12.8 & 29.4 & & & \\
\hline
\end{tabular}

